University of Wollongong

Research Online

Faculty of Social Sciences - Papers (Archive) Faculty of Arts, Social Sciences \& Humanities

2010

Factors associated with HIV testing among public sector clinic attendees in Johannesburg, South Africa

Audrey Pettifor

University of North Carolina

Catherine L. Mac Phail

University of Wollongong, cmacphai@uow.edu.au

Sujit Suchindran

University of North Carolina

Sinead Delany-Moretlwe

University of The Witwatersrand

Follow this and additional works at: https://ro.uow.edu.au/sspapers

Part of the Education Commons, and the Social and Behavioral Sciences Commons

Research Online is the open access institutional repository for the University of Wollongong. For further information contact the UOW Library: research-pubs@uow.edu.au 


\title{
Factors associated with HIV testing among public sector clinic attendees in Johannesburg, South Africa
}

\author{
Abstract \\ Uptake of VCT remains low in many sub-Saharan African countries. Men and women aged 15 and older \\ were recruited from a family planning, STI, and VCT clinic in inner-city Johannesburg between 2004 and \\ 2005 to take part in a cross-sectional survey on HIV testing $(n=198)$. Fourty-eight percent of participants \\ reported previously testing for HIV and, of these, $86.9 \%$ reported disclosing their status to their sex \\ partner. In multivariable analyses, individuals whose partners had been tested for HIV were more likely to \\ have tested (AOR 2.92; 95\% Cl: 1.38-6.20). In addition, those who reported greater blame/ shame \\ attitudes towards people living with HIV/AIDS were less likely to have tested (AOR 0.35 ; $95 \%$ CI: 0.16 - \\ 0.77) while those reporting more equitable attitudes towards people living with HIV/AIDS were more likely \\ to have tested (AOR 2.87; 95\% Cl: 1.20-6.86). Promotion of and increased access to couples HIV testing \\ should be made available within the South African context.

\section{Disciplines} \\ Education | Social and Behavioral Sciences

\section{Publication Details} \\ Pettifor, A., MacPhail, C., Suchindran, S. \& Delany-Moretlwe, S. (2010). Factors associated with HIV testing \\ among public sector clinic attendees in Johannesburg, South Africa. AIDS and Behavior, 14 (4), 913-921.
}




\title{
Factors Associated with HIV Testing Among Public Sector Clinic Attendees in Johannesburg, South Africa
}

\author{
Audrey Pettifor · Catherine MacPhail · \\ Sujit Suchindran $\cdot$ Sinead Delany-Moretlwe
}

Published online: 18 October 2008

(C) Springer Science+Business Media, LLC 2008

\begin{abstract}
Uptake of VCT remains low in many subSaharan African countries. Men and women aged 15 and older were recruited from a family planning, STI, and VCT clinic in inner-city Johannesburg between 2004 and 2005 to take part in a cross-sectional survey on HIV testing $(n=198)$. Fourty-eight percent of participants reported previously testing for HIV and, of these, $86.9 \%$ reported disclosing their status to their sex partner. In multivariable analyses, individuals whose partners had been tested for HIV were more likely to have tested (AOR 2.92; 95\% CI: 1.38-6.20). In addition, those who reported greater blame/ shame attitudes towards people living with HIV/AIDS were less likely to have tested (AOR 0.35 ; $95 \%$ CI: $0.16-$ 0.77) while those reporting more equitable attitudes towards people living with HIV/AIDS were more likely to have tested (AOR 2.87; 95\% CI: 1.20-6.86). Promotion of and increased access to couples HIV testing should be made available within the South African context.
\end{abstract}

Keywords HIV $\cdot$ VCT $\cdot$ Stigma $\cdot$ Couples $\cdot$ South Africa

\footnotetext{
A. Pettifor $(\bowtie)$

Department of Epidemiology, University of North Carolina, CB \#7435, McGavran-Greenberg Bldg, Chapel Hill, NC 27599-7435, USA

e-mail: apettif@email.unc.edu

C. MacPhail $\cdot$ S. Delany-Moretlwe

Reproductive Health and HIV Research Unit, University of the Witwatersrand, Johannesburg, South Africa

S. Suchindran

School of Medicine, University of North Carolina, Chapel Hill, NC, USA
}

\section{Background}

Voluntary testing and counseling (VCT) for HIV has been promoted as an important tool for preventing the further spread of HIV through behavior change (The voluntary HIV-1 counseling, testing efficacy study group 2000) and as an entry point for care and treatment of individuals who are infected (Valdiserri et al. 1999). VCT has been found to reduce high risk behaviors in individuals who are HIV positive (The voluntary HIV-1 counseling, testing efficacy study group 2000). However, similar effects are not as convincing for the large proportion who test negative. A recent study found increased risk behaviors in HIV negative individuals after undergoing VCT (Sherr et al. 2007) while a comparison of two VCT strategies in Zimbabwe found that despite improved acceptability of the trial VCT strategy, risk behaviors continued in individuals testing negative following their diagnosis (Corbett et al. 2007). Although there has been a focus on increasing the number of people undergoing HIV testing and counseling, currently less than a quarter of HIV positive individuals in most countries in sub-Saharan Africa are aware of their status (WHO, UNAIDS and UNICEF 2007).

Alongside expanded rollout of antiretroviral treatment in South Africa, there has been an expansion of sites providing VCT (Shisana and Simbayi 2002). However, uptake of VCT remains limited in many settings, even when available (Kalichman and Simbayi 2003). Stigma and negative attitudes towards HIV testing play an important role in the limited uptake of VCT in South Africa (Mwamburi et al. 2005; Smith and Morrison 2006). Additionally, attitudes towards availability of HIV treatment and perceptions of HIV-associated stigma may also affect individuals' perceptions of the value of knowing their status and therefore their uptake of testing. Better 
understanding of factors that may facilitate or impede the uptake of testing is important so that programs can more effectively encourage individuals to learn their HIV status. In this paper we aim to describe the testing patterns of a public sector clinic population in inner-city Johannesburg and to identify factors associated with HIV testing.

\section{Methods}

Individuals attending Esselen Street Clinic were recruited to take part in an interviewer administered, structured questionnaire on HIV testing and attitudes towards testing. The clinic is located within an inner-city neighborhood of downtown Johannesburg (Hillbrow) characterized by high unemployment, poverty, and overcrowding of high-rise residential buildings. Esselen Street Clinic provides routine primary health care for sexually transmitted infections (STI), tuberculosis, family planning, and VCT for HIV. From September 2004 until January 2005 individuals attending pre-test counseling for VCT, for family planning or STI treatment were recruited to take part in the survey. Participants were purposively sampled so that approximately half of all participants were recruited from the VCT clinic and the other half were from the family planning and STI clinic. Individuals who were 15 years or older and who provided written informed consent took part in the interview. Individuals recruited from the VCT clinic were interviewed before they underwent VCT.

The questionnaire covered topics with regard to demographics, socio-economic status, HIV testing history, HIV stigma, disclosure of status, social support and negative life events, and community norms with regard to HIV testing.

\section{Measures}

Questions on HIV testing were drawn primarily from the Project Accept (HPTN 043) baseline questionnaire (Project Accept). We assessed HIV testing history (age of first test, number of tests ever and in past 12 months, reasons for testing, place of testing, time since last test, receipt of test results, result of last test), history of disclosure of test results (who disclosed to, result of disclosure), change in sexual behavior due to test results and sex partners' testing history. We also measured perceived norms around HIV testing and the perceived impact of availability of ARVs on HIV testing.

We measured HIV/AIDS-related stigma and discrimination using a 22-item brief stigma scale developed by Genberg et al. (Genberg et al. 2008). The scale has three underlying dimensions-shame/blame/social isolation, discrimination and equity. The shame/blame/social isolation subscale has 10 -items, the discrimination subscale has
8 -items and the equity subscale has 5 -items. We did not validate the scale in our population; however, it has been validated in Zimbabwe and Thailand with fairly high internal consistency in each dimension (alphas from .71 to .86 for each part of the scale) (Genberg et al. 2008). The scale is also currently being used in a multi-site randomized controlled intervention trial designed to test the efficacy of a community level VCT intervention (Project Accept), which includes sites in South Africa, Zimbabwe and Tanzania. Each question in the scale used a 4-point Likert scale ranging from strongly agree (coded as 4) to strongly disagree (coded as 1). We dichotomized the scales into high and low based on the median values and distribution of the data. The shame/blame scale was dichotomized as $<3.4$ (high shame/blame) and 3.4-4.0 (low shame/blame), for discrimination $\leq 2.25$ (high discrimination) and $>2.25$ (low discrimination), and equity as $<3.4$ (low equity) and 3.4-4.0 (high equity).

Socioeconomic status (SES) was measured based on respondents' reported ownership of household durables (not education). On this 20 point scale, a score of $0-7$ was deemed "Lower SES", 8-13 was deemed "Middle SES" and a score of 14-20 was deemed "Higher SES".

The main outcome for this analysis was a history of HIV testing. Individuals were asked "Have you ever been tested for HIV previously" (yes/no). We did not count the current visit as a test for those who were recruited from the VCT clinic as individuals may have refused testing during the pre-test counseling and many questions were asked in relation to experiences as a result of their testing (i.e., disclosure or negative life events).

\section{Data Analysis}

Data analysis was conducted in Stata 9.2. Bivariate analysis was first conducted to examine factors associated with having ever tested for HIV infection. A final multivariable logistic regression model was created using manual backwards elimination, keeping a priori decided sociodemographic variables in the model and those variables which were statistically significant $(P<0.05)$.

\section{Results}

One hundred and ninety eight individuals were recruited to take part in the study. Participants were young (mean age: 24.5), all were Black African and $46 \%$ had completed high school. The majority $(80 \%)$ had either a boyfriend or girlfriend (61\% reported not co-habiting); only $8 \%$ were married and $12 \%$ reported not currently having a partner. Using an asset list, $76 \%$ of respondents reported owning 8-13 out of 20 -items, classified as middle socio-economic status; $12 \%$ 
owned the lower third of items (0-7), and $12 \%$ were in the upper third (14-20-items). 47\% reported being unemployed, $21 \%$ were employed full time, $11 \%$ were employed part time, $7 \%$ were self-employed and $17 \%$ were students. Fiftyseven percent of respondents reported having worked for pay in the past 3 months.

Forty eight point five percent of all participants reported that they had ever tested for HIV previously (Table 1). The mean age of first HIV test was 20.8 years for women and 24.4 years for men. Of those that had tested for HIV previously, the mean number of previous tests was 1.97 with $42.8 \%$ of this group having had a test within the past year. Fifty four percent of individuals recruited from the VCT clinic reported having tested previously compared to $43 \%$ of those recruited from the Family Planning/STI clinic. The majority $(64.6 \%)$ reported having tested at a public clinic and almost all (96.9\%) reported that they received the results of their most recent HIV test. Of those who reported having tested, $35.4 \%$ reported having tested because they wanted to know their HIV status, $26.2 \%$ of women reported they were tested during pregnancy, $16.7 \%$ reported being concerned about their own or their partners sexual behavior and $12.5 \%$ reported it was because they were sick (Table 1).

Of those who reported never having tested for HIV previously, the most common reason reported for not testing was that they were afraid or nervous to be tested $(51 \%)$. This was followed by $28.6 \%$ who reported that they had never thought of getting tested before, $15.3 \%$ who said they did not think they were at risk for HIV, and $5.1 \%$ who reported not having enough time to test. Less than $2 \%$ of participants reported other reasons for not testing such as being worried about their sex partner's reaction, worried people would think they are sick and that the testing site is too far from home.

The majority (90.3\%) of those who had tested for HIV reported having told someone the result of their last test with $86.9 \%$ telling a main partner or spouse and $76.2 \%$ telling a family member. Two-thirds reported telling a friend their result and almost the same proportion disclosed to a health care worker (Table 1). When asked if sex partners supported them more, less or about the same as before they disclosed their HIV status, 53.6\% said partners were more supportive, $23.8 \%$ the same and $9.5 \%$ less supportive. Of those that had disclosed to a main partner, $46.6 \%$ reported that they started using condoms as a result and $43.8 \%$ reported that their partner also went for HIV testing; $8.2 \%$ reported that their relationship ended as a result of disclosure and $4.1 \%$ reported being physically hurt as a result. When asked whether their sexual behavior had changed in anyway after receiving their last test results, $38.7 \%$ reported that they started using condoms and $19.4 \%$ reported that they became monogamous. A small percentage $(7.5 \%)$ reported that they stopped having sex after HIV testing.

Of the three dimensions that comprised the stigma scale (Table 1), the mean scores for the equity and blame/shame scale were relatively high, 3.50 and 3.45 , respectively (range: 1-4). According to the dichotomous cut-offs allocated to the scales this translates into high levels of equity and low levels of blame/shame in this population. The mean score for the discrimination scale was more than a whole point lower at 2.31 .

When asked about perceived norms with regard to HIV testing (Table 2), the vast majority (92.4\%) strongly agreed/agreed that most people are afraid to get tested for HIV and $94 \%$ strongly agreed/agreed that most people who test do not want others to find out they were tested. The majority (83.3\%) thought most people only test for HIV if they are sick and only $39.4 \%$ thought most people want to get tested for HIV. When asked about perceived effectiveness, affordability and availability of ARVs, 75.1\% thought ARVs were effective, 56.3\% thought they were affordable but only $24.9 \%$ thought ARVs were easily available in the community (Table 2 ).

Table 3 shows bivariate associations between having tested for HIV and potential predictive variables. Factors that were significantly associated with having tested for HIV included: having a partner who had been tested for HIV, agreeing that most people only test for HIV if they are sick; disagreeing that most people want to test for HIV; agreeing that they would be more willing to test if ARVs are easily available; scoring high on the equity dimension of the stigma scale; scoring low on the blame/shaming attitude dimension of the stigma scale (Table 3 ).

In the final logistic regression model (Table 4), two of the measures of stigma, the measures of shame and of equity, were significantly associated with having tested for HIV. Those who reported more blame/shame attitudes $(<3.4)$ were less likely to have had an HIV test (AOR 0.35; 95\% CI: 0.16-0.77). Those who reported more equitable views towards those with HIV/AIDS ( $>3.4)$, were more likely to have had an HIV test (AOR 2.87; 95\% CI: 1.20 6.86). Having a partner who had been tested for HIV was also significantly associated with the individual having tested for HIV (AOR 2.92; 95\% CI: 1.38-6.20). In addition, those who reported that they would be more willing to test for HIV if ARVs were more easily available were also more likely to have tested for HIV (AOR 2.91; 95\% CI: 1.12-7.53). Surprisingly, respondents who did not think most people wanted to get HIV tests were actually more likely to have had a previous test (AOR 2.59; 95\% CI: 1.29-5.24). In addition, respondents who thought that people were more likely to test if they were sick were also more likely to have tested (AOR 4.66; 95\% CI: 1.70 12.76). 
Table 1 HIV testing history, outcomes of disclosure, attitudes towards testing and perceived stigma by gender among a clinic population in Johannesburg, South Africa, 2004

\begin{tabular}{|c|c|c|c|}
\hline & Total \% $(n)$ & Males $\%(n)$ & Females $\%(n)$ \\
\hline \multicolumn{4}{|l|}{ Ever tested for HIV $(n=198)$} \\
\hline Yes & $48.5(96)$ & $47.3(35)$ & $49.2(61)$ \\
\hline No & $51.5(102)$ & $52.7(39)$ & $50.8(63)$ \\
\hline Age of first HIV test $(n=96)$ & $22.1(4.5)$ & $24.4(5.4)$ & $20.8(3.4)$ \\
\hline \multicolumn{4}{|l|}{ Mean (SD) } \\
\hline Number of previous HIV tests $(n=96)$ & $1.97(1.45)$ & $2.49(1.69)$ & $1.67(1.22)$ \\
\hline \multicolumn{4}{|l|}{ Mean (SD) } \\
\hline Number of HIV tests in past 12 months $(n=96)$ & $0.68(.75)$ & $0.69(.87)$ & $0.67(.68)$ \\
\hline \multicolumn{4}{|l|}{ Mean (SD) } \\
\hline \multicolumn{4}{|l|}{ Results of last test $(n=92)$} \\
\hline Positive & $17.4(16)$ & $14.7(5)$ & $19.0(11)$ \\
\hline Negative & $79.3(73)$ & $82.4(28)$ & $77.6(45)$ \\
\hline Refused to answer & $3.3(3)$ & $2.9(1)$ & $3.5(2)$ \\
\hline \multicolumn{4}{|l|}{ Reason for most recent testing $(n=96)$} \\
\hline Wanted to know HIV status & $35.4(34)$ & $40.0(14)$ & $32.8(20)$ \\
\hline Was pregnant & $16.7(16)$ & - & $26.2(16)$ \\
\hline Was sick (cough or 'sick') & $12.5(12)$ & $14.3(5)$ & $11.5(7)$ \\
\hline Concerned about own or partner's sexual behavior & $16.7(16)$ & $17.1(6)$ & $16.4(10)$ \\
\hline Got the results of most recent test & $96.9(93)$ & $97.1(34)$ & $96.7(59)$ \\
\hline \multicolumn{4}{|l|}{ Place of most recent HIV test $(n=96)$} \\
\hline Public clinic & $64.6(62)$ & $74.3(26)$ & $59.0(36)$ \\
\hline Hospital & $17.7(17)$ & $5.7(2)$ & $24.6(15)$ \\
\hline Private clinic & $12.5(12)$ & $14.3(5)$ & $11.5(7)$ \\
\hline other & $5.2(5)$ & $5.7(2)$ & $4.9(3)$ \\
\hline \multicolumn{4}{|l|}{ How long ago tested $(n=96)$} \\
\hline Within last month & $6.3(6)$ & $11.4(4)$ & $3.3(2)$ \\
\hline 1-12 months ago & $36.5(35)$ & $37.2(13)$ & $36.1(22)$ \\
\hline$>1$ year ago & $57.4(55)$ & $51.4(18)$ & $60.7(37)$ \\
\hline Told someone result of last HIV test $(n=93)$ & $90.3(84)$ & $91.2(31)$ & $89.8(53)$ \\
\hline \multicolumn{4}{|l|}{ Person disclosed status to $(n=84)$} \\
\hline Spouse/main partner & $86.9(73)$ & $83.8(26)$ & $88.7(47)$ \\
\hline Other sexual partner & $9.5(8)$ & $22.6(7)$ & $1.9(1)$ \\
\hline Family member & $76.2(64)$ & $71.0(22)$ & $79.3(42)$ \\
\hline Friends & $66.7(56)$ & $67.7(21)$ & $66.0(35)$ \\
\hline Health care worker & $61.9(52)$ & $51.6(16)$ & $67.9(36)$ \\
\hline Religious leader & $8.3(7)$ & $16.1(5)$ & $3.8(2)$ \\
\hline Employer & $10.7(9)$ & $22.6(7)$ & $3.8(2)$ \\
\hline \multicolumn{4}{|l|}{ Results of disclosure to main partner $(n=73)$} \\
\hline Stopped having sex & $17.8(13)$ & $19.2(5)$ & $17.0(8)$ \\
\hline Relationship ended & $8.2(6)$ & $15.4(4)$ & $4.3(2)$ \\
\hline Started using condoms with spouse/main partner & $46.6(34)$ & $53.9(14)$ & $42.6(20)$ \\
\hline Got physically hurt by partner & $4.1(3)$ & $3.9(1)$ & $4.3(2)$ \\
\hline Sexual partner also went for testing & $43.8(32)$ & $50.0(13)$ & $40.4(19)$ \\
\hline \multicolumn{4}{|c|}{ Did sexual behavior change in anyway after receiving results of last test $(n=93)$} \\
\hline Stopped having sex & $7.5(7)$ & $8.8(3)$ & $6.8(4)$ \\
\hline Started using condoms & $38.7(36)$ & $32.4(11)$ & $42.4(25)$ \\
\hline Reduced number of partners & $9.7(9)$ & $20.6(7)$ & $3.4(2)$ \\
\hline Became monogamous & $19.4(18)$ & $14.7(5)$ & $22.0(13)$ \\
\hline Continued not using condoms & $14.0(13)$ & $3.0(1)$ & $20.3(12)$ \\
\hline
\end{tabular}


Table 1 continued

\begin{tabular}{lllc}
\hline & Total \% $(n)$ & Males \% (n) & Females \% (n) \\
\hline $\begin{array}{l}\text { Respondent thinks ARVs would be available } \\
\text { if he/she was HIV positive }(n=198)\end{array}$ & $70.7(140)$ & $67.6(50)$ & $72.6(90)$ \\
$\begin{array}{l}\text { Respondent would be more willing to be tested } \\
\quad \text { if ARVs easily available }(n=198)\end{array}$ & $83.3(165)$ & $77.0(57)$ & $87.1(108)$ \\
Partner been tested for HIV ( $n=198)$ & & & \\
$\quad$ Yes & & & \\
$\quad$ No & $40.4(80)$ & $36.5(27)$ & $42.7(53)$ \\
$\quad$ Do not know & $37.4(74)$ & $31.1(23)$ & $41.1(51)$ \\
$\quad$ No partner & $10.6(21)$ & $10.8(8)$ & $10.5(13)$ \\
Partner tested for HIV and told responder & $92.5(74)$ & $21.6(16)$ & $5.7(7)$ \\
$\quad$ his/her status $(n=80)$ & $3.50(.41)$ & $3.52(.36)$ & $3.48(.44)$ \\
Equity scale: mean (SD) (range 1-4) & $3.45(.37)$ & $3.44(.40)$ & $3.46(.35)$ \\
Blame/shame scale: mean (SD) (range 1-4) & $2.31(.47)$ & $2.35(.46)$ & $2.29(.48)$ \\
Discrimination scale: mean (SD) (range 1-4) & &
\end{tabular}

Table 2 Perceived norms with regard to HIV testing and attitudes with regard to ARVs and HIV testing in Johannesburg, South Africa, 2004

\begin{tabular}{|c|c|c|c|c|}
\hline$\%(n) N=198$ & Strongly agree & Agree & Disagree & Strongly disagree \\
\hline Most people who want to get tested are afraid to get tested & $49.5(98)$ & $42.9(85)$ & $5.6(11)$ & $2.0(4)$ \\
\hline Most people who get tested do not want others to find out they were tested & $38.4(76)$ & $55.6(110)$ & $4.0(8)$ & $1.5(3)$ \\
\hline Most people who want to get tested will tell their partners they want to get tested & $11.6(23)$ & $46.0(91)$ & $36.9(73)$ & $5.0(10)$ \\
\hline Most people want to get tested for HIV & $11.6(23)$ & $27.8(55)$ & $39.9(79)$ & $19.7(39)$ \\
\hline Most people have been tested for HIV & $8.6(17)$ & $38.9(77)$ & $40.9(81)$ & $10.6(21)$ \\
\hline Most people get tested for HIV only if they are sick & $49.0(97)$ & $34.3(68)$ & $13.6(27)$ & $3.0(6)$ \\
\hline ARVs are effective & $15.2(30)$ & $59.9(118)$ & $11.7(23)$ & $2.5(5)$ \\
\hline ARVs are affordable & $9.6(19)$ & $46.7(92)$ & $33.5(66)$ & $6.6(13)$ \\
\hline ARVs easily available in community & $4.1(8)$ & $20.8(41)$ & $43.2(85)$ & $25.9(51)$ \\
\hline
\end{tabular}

\section{Discussion}

In this clinic based population, we found that close to half $(48.5 \%)$ of the population reported a history of HIV testing. This is higher than that reported in a national household survey conducted in 2005 where only $30 \%$ of respondents reported having been tested for HIV (Shisana and Simbayi 2005). However, this figure is close to the percentage reporting having been previously tested for HIV among participants recruited from multiple venues in Cape Town, South Africa (47\% reported having been tested previously) (Kalichman and Simbayi 2003). The difference in the percentage who report having previously tested may be due to the difference in sampling venues; the lower percentage in the household survey likely reflects the inclusion of individuals with less access to health care services. Mean age of first test for both men and women is relatively high given that the mean age of first sex in South Africa is 16.4 and 16.8, respectively, and that the prevalence of HIV is already high by the age of 20, particularly among women (Pettifor et al. 2005). For women, who are likely to test during routine antenatal care (MacPhail et al. 2008a), the mean age of first test is higher than the mean age of first pregnancy (Pettifor et al. 2005). Participants who reported not testing previously were most likely to report fear as the main factor preventing them from accessing testing. Although the survey instrument did not determine the source of such fear, research in sub-Saharan Africa has indicated that despite treatment availability, the potential for a positive HIV test result is a significant barrier to testing (MacPhail et al. 2008a, b; Morin et al. 2006). Our previous research with South African adolescents has shown an overwhelming fear of the psychological impacts of learning that one is HIV positive, with many believing that this will lead to suicide and a more rapid decline to AIDS and death (MacPhail et al. 2008a). Previous researchers have noted that a fear of the social consequences of being HIV positive was a significant barrier to HIV testing (Link and Phelan 2001). In a study of the barriers to testing among South African women disclosing to partners, fear of rejection, stigma and gossip were noted as significant barriers (Sigxashe et al. 2001). 
Table 3 Unadjusted logistic regression model for candidate factors associated with having previous HIV test in Johannesburg, South Africa, 2004

\begin{tabular}{|c|c|}
\hline & OR $(95 \% \mathrm{CI})$ \\
\hline \multicolumn{2}{|l|}{ Age } \\
\hline $16-24$ & $0.82(0.40,1.68)$ \\
\hline $25-42$ & 1.00 \\
\hline \multicolumn{2}{|l|}{ Sex } \\
\hline Male & $1.57(0.69,3.56)$ \\
\hline Female & 1.00 \\
\hline \multicolumn{2}{|l|}{ Relationship status } \\
\hline $\begin{array}{l}\text { Living together (married or with boy/ } \\
\text { girlfriend) }\end{array}$ & 1.00 \\
\hline $\begin{array}{l}\text { Not living together (with spouse or boy/ } \\
\text { girlfriend) }\end{array}$ & $0.85(0.39-1.86)$ \\
\hline No current partner & $1.53(0.42-5.58)$ \\
\hline \multicolumn{2}{|l|}{ Education } \\
\hline$<$ High school & 1.00 \\
\hline$\geq$ High school & $0.48(0.22-1.04)$ \\
\hline \multicolumn{2}{|l|}{ Socio-economic status } \\
\hline Low & 1.00 \\
\hline Medium & $1.05(0.33-3.35)$ \\
\hline High & $1.53(0.34-6.96)$ \\
\hline \multicolumn{2}{|l|}{ Equity scale } \\
\hline$<3.4$ (low equity) & 1.00 \\
\hline 3.4-4.0 (high equity) & $2.85(1.17-6.90)$ \\
\hline \multicolumn{2}{|l|}{ Blame/shame scale } \\
\hline$<3.4$ (high blame/shame) & $0.35(0.16-0.78)$ \\
\hline 3.4-4.0 (low blame/shame) & 1.00 \\
\hline \multicolumn{2}{|l|}{ Discrimination scale } \\
\hline$>2.25$ (low discrimination) & $1.18(0.60-2.32)$ \\
\hline$\leq 2.25$ (high discrimination) & 1.00 \\
\hline \multicolumn{2}{|c|}{ People who want to get tested for HIV are afraid } \\
\hline Agree & 1.00 \\
\hline Disagree & $1.39(0.36-5.30)$ \\
\hline \multicolumn{2}{|l|}{ Most people want to get tested for HIV } \\
\hline Agree & 1.00 \\
\hline Disagree & $2.56(1.23-5.37)$ \\
\hline
\end{tabular}

Most people who want to get tested for HIV are afraid to get tested
Agree
1.00
Disagree
$1.40(0.33-5.89)$

Most people who get tested do not want others to find out they were tested
Agree
1.00
Disagree
$0.44(0.10-2.01)$

Most people who want to get tested will tell their partner they want to get tested
Agree
1.00
Disagree
$0.63(0.30-1.33)$
Most people have been tested for HIV
Agree
1.00
Disagree
$1.03(0.52-2.04)$

Table 3 continued

OR $(95 \% \mathrm{CI})$

Most people get tested for HIV only if they are sick

$\begin{array}{ll}\text { Agree } & 4.91(1.68-14.3) \\ \text { Disagree } & 1.00\end{array}$

ARVs are easily available in the community

Agree $\quad 1.00$

Disagree $\quad 0.48(0.20-1.13)$

ARVs are effective

Agree $\quad 1.00$

Disagree $\quad 0.82(0.29-2.32)$

ARVs are affordable

$\begin{array}{ll}\text { Agree } & 1.00 \\ \text { Disagree } & 1.72(0.73-4.04)\end{array}$

Would be more willing to be tested if ARVs are easily available

Agree

$2.88(1.12-7.45)$

Disagree

1.00

ARVs would be available if he/she were HIV positive

$\begin{array}{ll}\text { Agree } & 1.24(0.65-2.39) \\ \text { Disagree } & 1.00 \\ \text { Partner has been tested for HIV } & \\ \text { Yes } & 3.07(1.41-6.65) \\ \text { Does not know } & 1.28(0.36-4.53) \\ \text { No } & 1.00 \\ \text { linic recruited from } & 1.55(0.88-2.72) \\ \text { VCT } & 1.00 \\ \text { Family planning/STI } & \end{array}$

Among those who reported having previously tested for HIV, a remarkable $90.3 \%$ of individuals reported having disclosed their status to someone and, of those that had disclosed, the vast majority $(86.9 \%)$ had disclosed to a sex partner; this did not differ by gender. This is an encouraging finding given the fear of stigma and discrimination surrounding HIV in South Africa and confirms findings from other African countries. King et al. in Uganda found that $69 \%$ of HIV-infected individuals had disclosed their status to their most recent sex partner (King et al. 2008) and Maman et al. in Tanzania found that $64 \%$ of HIVinfected women and $79.5 \%$ of HIV negative women reported having shared their status with their sex partners (Maman et al. 2003). However, disclosure rates are not this high in all populations. In a review of disclosure levels among pregnant women in Africa, rates of women who chose not to disclose their status to partners varied between $16.7 \%$ and $86 \%$ (Medley et al. 2004).

The factor most strongly associated with having tested for HIV was having a partner who had tested. In addition, close to $44 \%$ of participants reported that a partner went for testing as a result of their status disclosure. Similar findings 
Table 4 Multivariable logistic regression model for factors associated with having tested for HIV, Johannesburg, South Africa, 2004

\begin{tabular}{|c|c|}
\hline & OR $(95 \% \mathrm{CI})$ \\
\hline \multicolumn{2}{|l|}{ Age } \\
\hline $16-24$ & $0.82(0.41-1.65)$ \\
\hline $25-42$ & 1.00 \\
\hline \multicolumn{2}{|l|}{ Sex } \\
\hline Male & $1.66(0.76-3.64)$ \\
\hline Female & 1.00 \\
\hline \multicolumn{2}{|l|}{ Socio-economic status } \\
\hline Low & 1.00 \\
\hline Medium & $1.11(0.38-3.29)$ \\
\hline High & $1.57(0.38-6.52)$ \\
\hline \multicolumn{2}{|l|}{ Education } \\
\hline$<$ High school & 1.00 \\
\hline$\geq$ High school & $0.47(0.22-0.98)$ \\
\hline \multicolumn{2}{|l|}{ Equity scale } \\
\hline$<3.4$ (low equity) & 1.00 \\
\hline 3.4-4.0 (high equity) & $2.87(1.20-6.86)$ \\
\hline \multicolumn{2}{|l|}{ Blame/shame scale } \\
\hline$<3.4$ (high blame/shame) & $0.35(0.16-0.77)$ \\
\hline 3.4-4.0 (low blame/shame) & 1.00 \\
\hline \multicolumn{2}{|c|}{ Most people want to get tested for HIV } \\
\hline Agree & 1.00 \\
\hline Disagree & $2.59(1.29-5.24)$ \\
\hline \multicolumn{2}{|c|}{ Most people get tested only if they are sick } \\
\hline Agree & $4.66(1.70-12.76)$ \\
\hline Disagree & 1.0 \\
\hline \multicolumn{2}{|c|}{ More willing to get tested if ARVs are easily available } \\
\hline Agree & $2.91(1.12-7.53)$ \\
\hline Disagree & 1.00 \\
\hline \multicolumn{2}{|l|}{ Partner has been tested for HIV } \\
\hline Yes & $2.92(1.38-6.20)$ \\
\hline No & 1.00 \\
\hline \multicolumn{2}{|l|}{ Location of recruitment } \\
\hline VCT & $1.97(1.00-3.87)$ \\
\hline Family planning/STI & 1.00 \\
\hline
\end{tabular}

have been reported from Uganda where knowledge of a partner's serostatus (a proxy for having tested) was significantly associated with disclosure of the individual's status (King et al. 2008). Couples testing is not routinely offered in the clinic from which these participants were recruited, although attempts are being made to expand this service. Qualitative research in Kenya found that men reported using couples testing to disclose their status to their partners, even when they already knew their status, as a means of avoiding face-to-face disclosure (Miller and Rubin 2007). Anecdotal evidence from other studies being conducted at the public health clinic where this data was collected indicates that this is also the case in this setting, and is not limited only to men. Importantly, we found that only $4.1 \%$ of participants reported being physically hurt as a result of disclosing their status to their partner and 8.2\% reported that the relationship ended. Generally, the majority of participants reported that partners were more supportive as a result of disclosure of their status. Couples counseling may further defer blame by removing the assumption that the partner who discovers their HIV status first is the partner who brought HIV into the relationship (King et al. 2008). Couples counseling in Zambia has also been associated with increased condom use among discordant couples, although consistent condom use was imperfectly maintained (Allen et al. 2003). Recent mathematical modeling using data from Zambia and Rwanda indicates that most heterosexual HIV transmission takes place within marriage or cohabiting relationships (Dunkle et al. 2008). Encouraging partners to test together is therefore an important strategy for African countries to consider implementing more widely, given the high levels of HIV-discordancy in stable heterosexual relationships (Allen et al. 2007; Painter 2001). It is vital, however, that couples voluntary counseling and testing receives endorsement from government and community leaders, while health care providers are capacitated to provide this service (Allen et al. 2007).

Measures of HIV/AIDS stigma were also significantly associated with having tested for HIV. Individuals with more equitable views around how people with HIV/AIDS should be treated were more likely to have tested for HIV and those with more blame/shaming attitudes were less likely to have tested. Similar findings have been noted from a study in Cape Town, where individuals who reported greater AIDS-related stigmas were also less likely to have tested (Kalichman and Simbayi 2003). Overall, mean scores for the shame/blame dimension of the stigma scale indicated relatively low levels of shaming attitudes towards people with HIV/AIDS among this population. For example, most people did not agree with the statements "people living with HIV/AIDS should be ashamed" and "people living with HIV/AIDS deserve to be punished". In addition, mean equity scores were relatively high; thus people agreed with statements such as "people with HIV should be allowed to participate fully in the social events in this community" and "people who have HIV/AIDS should be treated the same as everyone else". The mean discrimination score was lower. Interestingly, many of the questions that compose this dimension encompass how the community reacts to people with HIV/AIDS. Examples include "people living with HIV/AIDS face neglect from their families", "people who have HIV/AIDS face verbal abuse" and "people who are suspected of having HIV/ AIDS lose respect in the community". These findings indicate that individual self-perception of stigma towards 
HIV/AIDS is relatively low, however, perceptions of community level stigma towards people with HIV/AIDS is higher. These findings are further supported by the high percentage of individuals who reported that most people do not want others to know they have tested for HIV. Our previous research on VCT among adolescents in Johannesburg supports this view; participants were relatively certain of support and care from their families and friends but very concerned about potential discrimination from communities (MacPhail et al. 2008a, b). It is interesting that study participants reported low levels of stigmatizing attitudes in comparison to high reported levels of perceived stigma in the community. Further research should determine if these results hold in other populations in South Africa and, if so, should use this information to break down perceptions around AIDS stigma.

A number of attitudes towards testing were also significantly associated with having been tested for HIV. Individuals who had tested were more likely to perceive that "most people" do not want to get tested for HIV. Given that less than half of the population in this community had tested for HIV, it makes sense that those who have tested may perceive that others around them do not want to test. Individuals who had tested were also more likely to believe that people only test for HIV when they are sick. In qualitative research we have conducted in South Africa among youth attitudes towards testing, we also found the perception of testing only when individuals are sick to be common (MacPhail et al. 2008a). This is an interesting association given that only a small percentage of participants stated that being sick was their reason for their last HIV test. The association between testing and believing that others test when they are sick, although participants themselves do not report testing because of illness, this may reflect a sense among those who have tested that they tested for the "right" reasons while "others" wait until disease progression to test (Petros et al. 2006).

Lastly, individuals who had tested reported that they would be more willing to test if ARVS were easily available. Antiretroviral roll-out was initiated in the South African public sector in April of the same year that this study was conducted (Dalal et al. 2007), and at this stage was characterized by long waiting lists for treatment activation. This association may reflect higher levels of knowledge about availability of ARVs among the group who reported already having tested than those who had not been tested. A study among mineworkers in South Africa in 2001 found that only $14 \%$ of participants indicated that they would be more likely to use VCT services if ARVs were available (Day et al. 2003). However, the study was conducted in 2001 before the roll-out of ARVs in South Africa and the authors acknowledge that knowledge of
ARVs was likely low among the study participants. In the time since this study was conducted, ARVs have become increasingly available and the perceived benefit of ARVs and testing have potentially become more prominent. Given that these participants have already tested, this finding seems to indicate a willingness to test again in the future and may be a reflection of knowledge they have gained about HIV and treatment through having undergone a testing process previously as well as the greater prominence of ARVs in South African health settings more generally.

There are a number of limitations to this study. Firstly, it was a cross-sectional survey therefore we cannot determine any temporal associations between potential exposures and the outcome of testing. Secondly, as this was a clinic based sample, the prevalence of testing is likely higher than in the general population, specifically given that participants were purposefully recruited from the VCT clinic.

In this clinic based population in Johannesburg, disclosure of one's HIV status to sex partners was high and reports of negative events as a result were low. Having had a partner test for HIV was one of the factors most strongly associated with having tested for HIV. Given the importance of sex partners in transmitting the virus in this setting, couples testing should be more seriously considered as a strategy to increase testing in South Africa.

\section{References}

Allen, S., Karita, E., Chomba, E., Roth, D., Telfair, J., Zulu, I., et al. (2007). Promotion of couples' voluntary counselling and testing for HIV through influential networks in two African capital cities. BMC Public Health, 7, 349. doi:10.1186/1471-2458-7-349.

Allen, S., Meinzen-Derr, J., Kautzman, M., Zulu, I., Trask, S., Fideli, U., et al. (2003). Sexual behavior of HIV discordant couples after HIV counseling and testing. AIDS (London, England), 17(5), 733-740. doi:10.1097/00002030-200303280-00012.

Corbett, E. L., Makamure, B., Cheung, Y. B., Dauya, E., Matambo, R., Bandason, T., et al. (2007). HIV incidence during a clusterrandomized trial of two strategies providing voluntary counselling and testing at the workplace, Zimbabwe. AIDS (London, England), 21(4), 483-489. doi:10.1097/QAD.0b013e3280115402.

Dalal, R., MacPhail, C., Mqhayi, M., Wing, J., Feldman, C., Chersich, M., et al. (2007). Characteristics and outcomes of adult patients discontinuing follow-up at an antiretroviral treatment clinic in Johannesburg, South Africa. Journal of Acquired Immune Deficiency Syndromes, 47(1), 101-107.

Day, J. H., Miyamura, K., Grant, A. D., Leeuw, A., Munsamy, J., Baggaley, R., et al. (2003). Attitudes to HIV voluntary counselling and testing among mineworkers in South Africa: Will availability of antiretroviral therapy encourage testing? AIDS Care, 15(5), 665-672. doi:10.1080/0954012030001595140.

Dunkle, K. L., Stephenson, R., Karita, E., Chomba, E., Kayitenkore, K., Vwalika, C., et al. (2008). New heterosexually transmitted HIV infections in married or cohabiting couples in urban Zambia and Rwanda: An analysis of survey and clinical data. Lancet, 371(9631), 2183-2191. doi:10.1016/S0140-6736(08)60953-8. 
Genberg, B. L., Kawichai, S., Chingono, A., Sendah, M., Chariyalertsak, S., Konda, K. A., et al. (2008). Assessing HIV/AIDS stigma and discrimination in developing countries. AIDS and Behavior, 12(5), 772-780. doi:10.1007/s10461-007-9340-6.

Kalichman, S. C., \& Simbayi, L. C. (2003). HIV testing attitudes, AIDS stigma, and voluntary HIV counselling and testing in a black township in Cape Town, South Africa. Sexually Transmitted Infections, 79(6), 442-447. doi:10.1136/sti.79.6.442.

King, R., Katuntu, D., Lifshay, J., Packel, L., Batamwita, R., Nakayiwa, S., et al. (2008). Processes and outcomes of HIV serostatus disclosure to sexual partners among people living with HIV in Uganda. AIDS and Behavior, 12(2), 232-243. doi: 10.1007/s10461-007-9307-7.

Link, B. G., \& Phelan, J. C. (2001). Conceptualizing stigma. Annual Review of Sociology, 27, 363-385. doi:10.1146/annurev.soc.27. 1.363 .

MacPhail, C., Pettifor, A., Coates, T., \& Rees, H. (2008a). 'You must do the test to know your status': Attitudes to voluntary counseling and testing for HIV among South African youth and their parents. Health Education \& Behavior, 35(1), 87-104. doi:10.1177/1090198106286442.

MacPhail, C., Pettifor, A., Moyo, W., \& Rees, H. (2008b). Factors associated with HIV testing among South African youth aged 15-24 years. AIDS Care (in press).

Maman, S., Mbwambo, J., Hogan, N., Weiss, E., Kilonzo, G., \& Sweat, M. (2003). High rates and positive outcomes of HIVserostatus disclosure to sexual partners: Reasons or cautious optimism from a voluntary counseling and testing clinics in Dar es Salaam, Tanzania. AIDS and Behavior, 7(4), 372-382. doi: 10.1023/B:AIBE.0000004729.89102.d4

Medley, A., Garcia-Moreno, C., McGill, S., \& Maman, S. (2004). Rates, barriers and outcomes of HIV serostatus disclosure among women in developing countries: Implications for prevention of mother-to-child transmission programmes. Bulletin of the World Health Organization, 82(4), 299-307.

Miller, A. N., \& Rubin, D. L. (2007). Factors leading to selfdisclosure of a positive diagnosis in Nairobi, Kenya: People living with HIV/AIDS in the sub-Sahara. Qualitative Health Research, 17(5), 586-598. doi:10.1177/1049732307301498.

Morin, S. F., Khumalo-Sakutukwa, G., Charlebois, E. D., Routh, J., Fritz, K., Lane, T., et al. (2006). Removing barriers to knowing HIV status: Same-day mobile HIV testing in Zimbabwe. Journal of Acquired Immune Deficiency Syndromes, 41(2), 218-224. doi: 10.1097/01.qai.0000179455.01068.ab.

Mwamburi, D., Dladla, N., Qwana, E., \& Lurie, M. (2005). Factors associated with wanting to know HIV results in South Africa. AIDS Patient Care and STDs, 19(8), 518-525. doi:10.1089/ apc.2005.19.518.
Painter, T. M. (2001). Voluntary counseling and testing for couples: A high-leverage intervention for HIV/AIDS prevention in subSaharan Africa. Social Science and Medicine, 53(11), 13971411. doi:10.1016/S0277-9536(00)00427-5.

Petros, G., Airhihenbuwa, C., Simbayi, L., Ramlagan, S., \& Brown, B. (2006). HIV/AIDS and 'othering' in South Africa: The blame goes on. Culture, Health \& Sexuality, 8(1), 67-77. doi:10.1080/ 13691050500391489.

Pettifor, A., Rees, H., Kleinschmidt, I., Steffenson, A., MacPhail, C., Hlongwa-Madikizela, L., et al. (2005). Young people's sexual health in South Africa: HIV prevalence and sexual behaviours from a nationally representative household survey. AIDS (London, England), 19, 1525-1534. doi:10.1097/01.aids.0000183129. 16830.06.

Project Accept. A Phase III randomized controlled trial of community mobilization, mobile testing, same-day results, and post-test support for HIV in sub-Saharan Africa and Thailand. http:// www.cbvct.med.ucla.edu/overview.html. Accessed 2007.

Sherr, L., Lopman, B., Kakowa, M., Dube, S., Chawira, G., Nyamukapa, C., et al. (2007). Voluntary counselling and testing: Uptake, impact on sexual behaviour, and HIV incidence in a rural Zimbabwean cohort. AIDS (London, England), 21(7), 851860. doi:10.1097/QAD.0b013e32805e8711.

Shisana, O., \& Simbayi, L. (2002). Nelson Mandela/HSRC study of HIV/AIDS. South African National HIV prevalence, behavioural risks and mass media household survey 2002. Cape Town: Human Sciences Research Council.

Shisana, O., \& Simbayi, L. (2005). Nelson Mandela/HSRC study of HIV/AIDS South African National HIV prevalence, behavioural risks and mass media household survey 2005. Cape Town: Human Sciences Research Council.

Sigxashe, T. A., Baggaley, R., \& Mathews, C. (2001). Attitudes to disclosure of HIV status to sexual partners. South African Medical Journal, 91(11), 908-909.

Smith, R., \& Morrison, D. (2006). The impact of stigma, experience, and group referent on HIV risk assessments and HIV testing intentions in Namibia. Social Science and Medicine, 63(10), 2649-2660. doi:10.1016/j.socscimed.2006.07.006.

The voluntary HIV-1 counseling, testing efficacy study group. (2000). Efficacy of voluntary HIV-1 counselling and testing in individuals and couples in Kenya, Tanzania, and Trinidad: A randomised trial. Lancet, 356, 103-112.

Valdiserri, R., Holtgrave, D., \& West, G. (1999). Promoting early HIV diagnosis and entry into care. AIDS (London, England), 13, 2317-2330. doi:10.1097/00002030-199912030-00003.

WHO, UNAIDS, \& UNICEF. (2007). Towards universal access: Scaling up priority HIV/AIDS interventions in the health sector. Geneva: World Health Organization. 